\title{
The Functional Benefit of Coffee for Being Healthy and Beautiful
}

\section{Rosa Lelyana*}

Medicine Faculty of Diponegoro University, Indonesia

\begin{abstract}
A healthy and beautiful body is a necessity for everyone. Coffee is a very popular beverage worldwide. Many of the world's people who love coffee but only some people who understand that coffee is able to provide health effects and beauty for the body. The advancement of science in terms of nanomedicine and nanotechnology will provide additional benefits so that coffee as a nanoparticle will increasingly provide wider health benefits for individuals with obesity and individuals without obesity/normal weight. The more modern lifestyles that food consumption shifts to fast food, less fiber or less consumption of vegetables and fruits, lack of exercise, lack of sleep and smoking, air pollution causes high levels of oxidative stress through internal and external factors of the body.
\end{abstract}

Oxidation stress is a condition of tissue oxidation imbalance due to oxygen molecular excess or ROS/Reactive Oxigen Species.

\section{Keywords: Nanomedicine; Nanotechnology; Nanoparticle}

\section{The Role of ROS as Degenerative Disease Promotor}

ROS is formed through endogenous processes and exogenous processes. Examples of the exogenous process of ROS formation are ultraviolet radiation and ionizing radiation [1-3]. Example Endogenous process as the originator of ROS form all body metabolism activity related to work of mitochondrial electron transport chain, work of cytochrome P450 system, activity of NADPH oxidase and enzyme myeloperoxidase and xanthin oxidase [2,3]. Increased ROS is excessive will result in oxidative stress resulting in the destruction of cellular macromolecules. Nucleic acid, proteins and lipids are some of the damage to cellular macromolecules [4,5]. Oxidation is easy to do on cell membranes because cell membranes contain unsaturated fatty acids. Oxidation of lipids there are 2, namely primary and secondary lipid oxidation. Primary lipid oxidation results in $\mathrm{LOOH}$ or lipid hydroperoxidation [6] which has the potential to oxidize [7] to form cytotoxic and genotoxic compounds $[8,9]$. Secondary lipid oxidation will produce LPO or lipid peroxidation products then produce radicals free so that degenerative diseases that will cause coronary heart disease, stroke and the problem of aging (Figure 1) [6].

\section{Stress Oxidative}

\section{The role of free fatty acid as degenerative disease promotor}

The nerve and hormonal complex will regulate the balance between the storage of triglycerides and lipolysis. Triglycerides themselves are energy substrates. Triglycerides can be used when triglycerides in adipose tissue have turned into fatty acids (these changes are called hydrolyzed). Changes of triglycerides into fatty acids assisted by hormone sensitive lipase. The fatty acids formed from triglyceride changes in adipose tissue, will exit from the adipose tissue to the blood circulation and are present in the blood plasma for 3-4 minutes. At rest, the fatty acid exits the adipose tissue faster than fatty acid oxidation [10]. Excessive fatty acids in the blood plasma will facilitate the work of fatty acids as an oxidizing energy substrate when responding to sudden changes in energy requirements. For example during sports activities, there is often a sudden increase in energy demand. However, not all fatty acids are oxidized so that the fatty acid must re-esterify triglycerides in adipose tissue, muscle and liver. Fatty acids become the main precursor of triglyceride synthesis of VLDL/Very Low Density in liver $[11,12]$.

\section{The role and benefit of coffee as degenerative disease preventif}

Coffee contains several main components such as phenolic acid [13] and caffeine [14]. It also contains vitamin $\mathrm{P}$ and caffeic acid. The function of caffeine stimulates catecholamines and adrenaline, then results in weight loss and prevent obesity risk (antiobesity). Caffeine ultimately inhibit lipid peroxidation and the occurrence of atherosclerosis (antioxidant). Effects of caffeine on obesity are to participate in splitting triacylglycerol into free fatty acids and glycerol. In addition, the benefit of caffeine also inhibits NFkB then inhibit COX2 or inhibit the role of pro-inflammatory so that the complaints such as pain in the joints due to obesity will decrease by itself after consuming coffee (anti-inflammatory). Caffeic acid itself serves as an immunomodulator through its role in inhibiting NFkB. Vitamin P from coffee is an antioxidant that has a role in inhibiting ROS resulting in inhibition of endothel dysfunction and ultimately to prevent the incidence of atherosclerosis. Chlorogenic acid's coffee will inhibits hyperuricemia by inhibiting excessive production of uric acid (antihyperuricemia). Actually uric acid is an endogenous antioxidant. In the condition of obesity is often accompanied by the occurrence of hyperglicemia resulting in oxygenation of LDL and eventually arise lipid peroxidation and atherosclerosis. But with coffee consumption, coffee drinking which contains chlorogenic acid eventually the incidence of hyperglicemia in a person with obesity will be inhibited, as well as the incidence of hyperuricemia and will no risk endothel dysfunction. Endothel dysfunction will cause atherosclerosis (Figure 2) [15].

In addition to functional benefits for the health of the body, coffee beans are still mudapun have benefits to health/beauty because of the macro and micronutrient content that affect the occurrence of lipolysis in the body. Several studies conducted on mice [16] showed

\footnotetext{
*Corresponding author: Rosa Lelyana, Medicine Faculty of Diponegoro University, Indonesia, Tel: 8157645736; E-mail: rl3lyana@gmail.com

Received: November 20, 2017; Accepted: November 25, 2017; Published: November 29, 2017

Citation: Lelyana R (2017) The Functional Benefit of Coffee for Being Healthy and Beautiful. J Nanomed Nanotechnol 8: 471. doi: 10.4172/2157-7439.1000471

Copyright: @ 2017 Lelyana R. This is an open-access article distributed under the terms of the Creative Commons Attribution License, which permits unrestricted use, distribution, and reproduction in any medium, provided the original author and source are credited.
} 


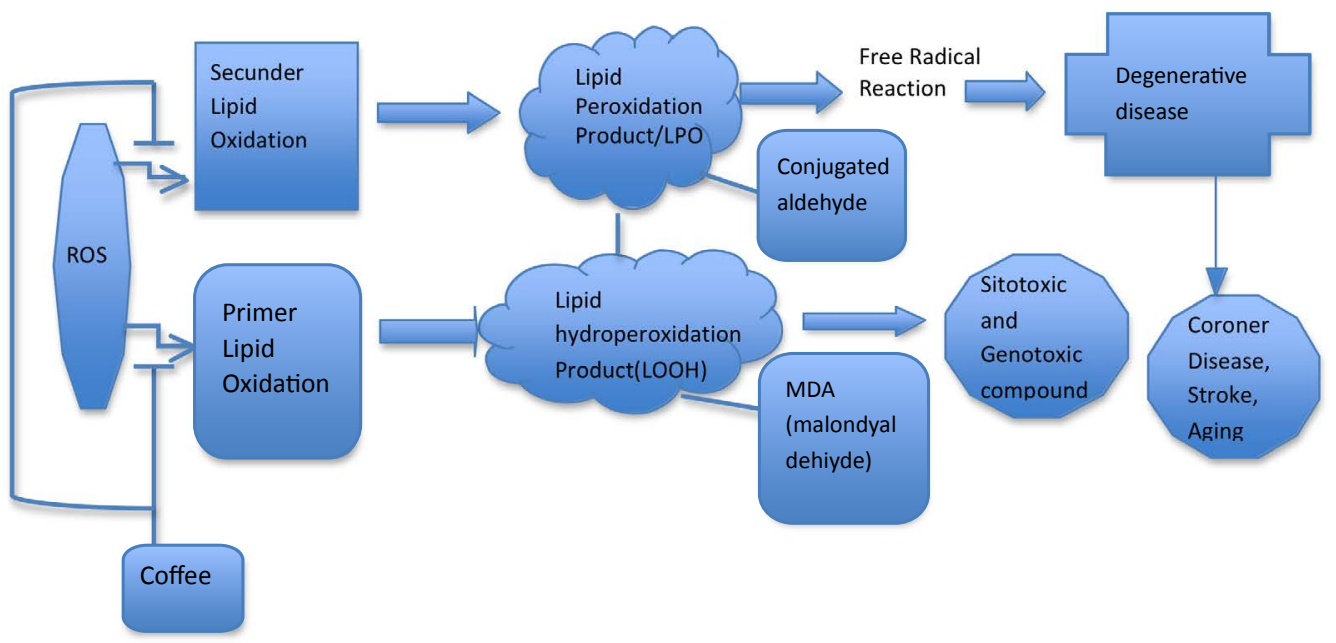

Figure 1: Secunder and primer lipid oxidation product as a good marker for stress oxidative.

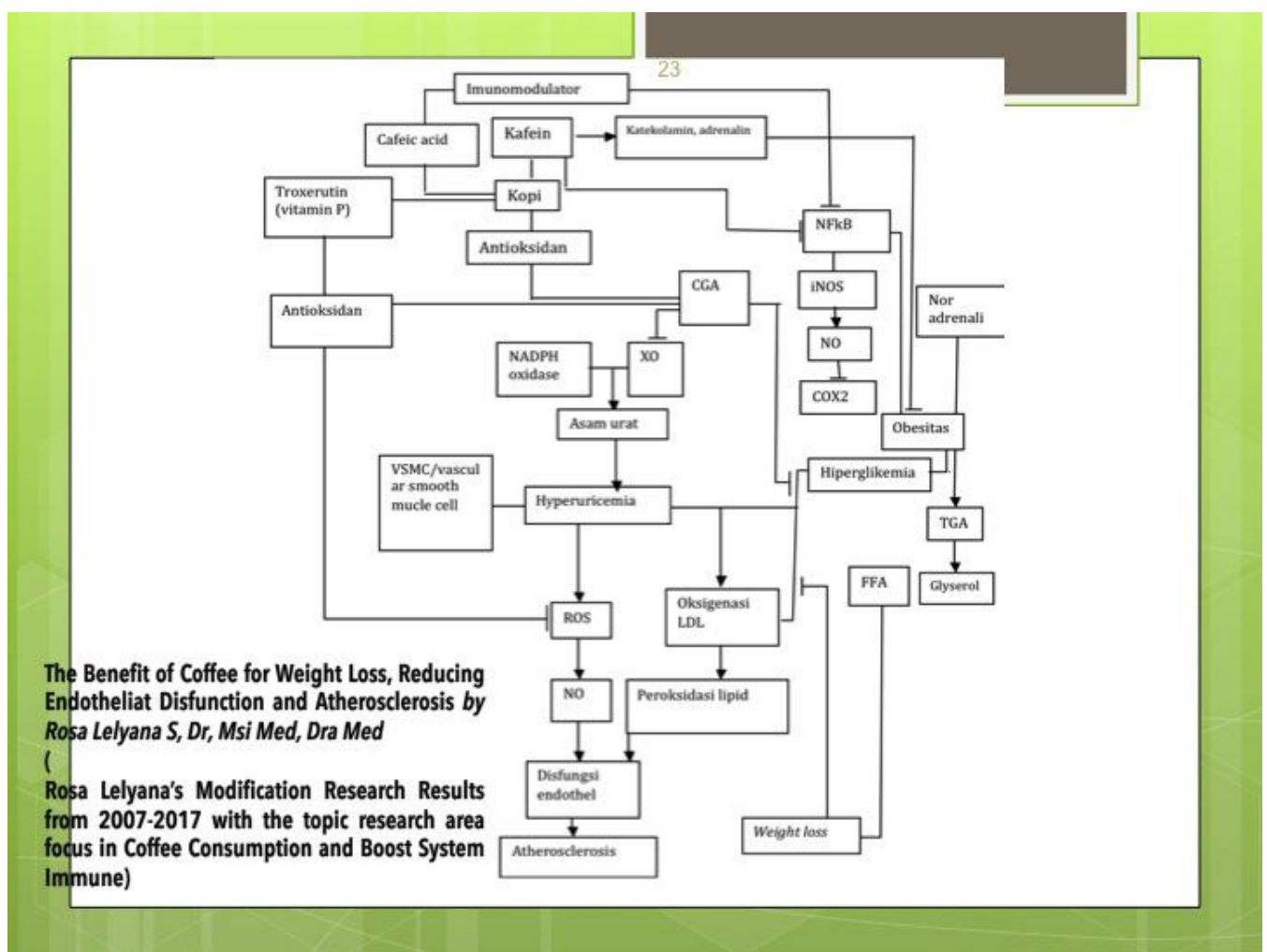

Figure 2: The functional of coffee which has antioxidant activity from Rosa Lelyana's modification of coffee and obesity results study from $2008-2012$ and the benefit of coffee for hyperuricemia, endothel dysfunction and weight loss by Lelyana [13]

that young coffee beans can inhibit fat metabolism in the liver. Study of consumption of extracted young coffee beans was carried out on mouse-fed animals for at least 6 days, 13 days and 14 days. The study was conducted with various doses of young coffee bean extraction thus providing a beneficial effect inhibiting fat metabolism [16].

Coffee can be used as a cosmetic (17). Ground coffee contains $15 \%$ coffee oil, of which $75 \%$ contains triacylglycerol, while some contain free fatty acids, waxes, sterols, tocopherol, ceramide, diterpenes and phosphatides [18]. Coffee oil has a content of linoleic acid and palmitic acid that is useful for skin inflammation and skin aging. It also has the ability to stimulate the formation of collagen, elastin and glicosaminoglican up to 2 -fold, as well as protection against UV rays or as Sun Protection Factor (SPF), reduce TEWL (trans epidermal water loss) so that body skin will be more beautiful and healthy [18].

So, coffee has various health benefits for the body predominantly when consumed every day and enough only 2 cups of coffee a day $[14,19]$. 
Citation: Lelyana R (2017) The Functional Benefit of Coffee for Being Healthy and Beautiful. J Nanomed Nanotechnol 8: 471. doi: 10.4172/21577439.1000471

Page 3 of 3

\section{References}

1. Mostafa Abd El-Aal HAH (2012) Lipid Peroxidation End-Products as a Key of Oxidative Stress: Effect of Antioxidant on Their Production and Transfer of Free Radicals. Biochemistry, Genetics and Molecular Biology.

2. Droge W (2002) Free Radicals in the physiological control of cell function. Physiol Rev 82: 47-95.

3. Jakus V (2000) The Role of Free Radicals, oxidative stress and antioxidant systems in diabetic vascular disease. Bratisl Lek Listy 101: 541-551.

4. Grundy SM (1998) Hypertriglyceridemia,atherogenic dyslipidemia, and the metabolic syndrome. Am J Cardiol 81: 18B-25B.

5. Stefan N, Kantartzis K, Haring HU (2008) Causes and Metabolic Consequences of Fatty Liver. Endocrine Reviews.

6. Mc Leod LL, Sevanian A (1997) Lipid Peroxidation and Modification of Lipid Composition in an Endothelial Cell Model of Ischemia and Reperfusion. Free Radic Biol Med 23: 680-694.

7. Kawakami A, Tanaka A, Nakano T, Nakajima K, Numano F (2000) The Role of Remnant Lipoproteins in Atherosclerosis. Annals of the New York Academy of Sciences.

8. Cnop M, Hannaert JC, Hoorens A, Eizirik DL, Pipeleers DG (2001) Inverse Relationship Between Cytotoxicity of FFA in Pancreatic Islet Cells and Cellular Triglyceride Accumulation. Diabetes 50: 1771-1777.

9. Pryor WA, Porter NA (1990) Suggested Mechanism for the Production of 4-hydroxy-2-nonenal from the Autoxidation of PUFA. Free Radic Biol Med 8: $541-543$

10. Johnston KL, Clifford MN, Morgan LM (2003) Coffee Acutely Modifies
Gastrointestinal Hormone Secretion and Glucose Tolerance in Humans:Glicemic Effects of Chlorogenic Acid and Caffeine. Am J Clin Nutr 78: 728-733.

11. Koutsari C, Mundi SM, Ali HA, Patterson BW, Jensen MD (2013) Systemic Free Fatty Acid Disposal Into VLDL Triglycerides. Diabetes Journal 62: 2386-2395.

12. Arbeeny CM, Meyers DS, Bergquist KE, Gregg RE (1992) Inhibition of Fatty Acid Synthesis Decreases VLDL Secretion in The Hamster. J Lipid Res 33: 843-851.

13. Lelyana R, Cahyono B (2015) Total phenolic acid contents in some commercial brands of coffee from Indonesia. J of Med Plant and Herb Ther Research 3: 27-29.

14. Lelyana R, Kopi P, Kadar T, Darah AU (2008) Studi Eksperimental Pada Rattus Norvegicus Galur WIstar. Diponegoro University, Semarang, Indonesia.

15. Lelyana R (2017) Biosynthesis of Nanoparticle Using Coffee Powder Extract $2^{\text {nd }}$ Asia Pacific Nano Biotechnology: BioLEAGUES International Interdisciplinary Conference, Singapore.

16. Shimoda H, Seki E, Aitani M (2006) Inhibitory Effect of Green Coffee Bean Extract on Fat Accumulation and Body Weight Gain in Mice. BMC Complement Altern Med 6: 9.

17. Rodrigues F, Palmeira-de-Oliveira A, das Neves J, Sarmento B, Amaral MH, et al. (2015) Coffee Silverskin: A possible valuable cosmetic ingredient. Journal Pharmaceutical Biology 53: 386-394.

18. Yang C, Hung C, Chen B (2017) Preparation of coffee oil-algae oil-based nanoemulsions and the study of their inhibition effect on UVA-induced skin damage in mice and melanoma cell growth. Int J Nanomedicine 2: 6559-6580.

19. Lelyana R (2016) Effect of Coffee Daily Consumption on Uric Acid Level and Body Weight to Prevent Metabolic Syndrome. J Nanomed Nanotechnol 7. 